\title{
High Calcium Transport by Polycystin-2 (TRPP2) Induces Channel Clustering and Coordinated Oscillatory Behavior
}

\author{
Irina F. Velázquez**, Horacio F. Cantiello and María del Rocío Cantero* \\ Laboratorio de Canales Iónicos, Instituto Multidisciplinario de Salud, Tecnología y Desarrollo \\ (IMSaTeD, CONICET-UNSE). Santiago del Estero, Argentina.
}

*Address correspondence to: María del Rocío Cantero. IMSaTeD (CONICET-UNSE), Laboratorios Centrales. Ruta Nacional Nº9, km 1125 S/N. Villa El Zanjón, Santiago del Estero, Argentina. E-mail: $\underline{\text { mdrcantero@gmail.com }}$

**Current Address: Instituto de Diversidad y Evolución Austral (IDEAus-CONICET), Bv. Almirante Brown 2915, Puerto Madryn, Chubut, Argentina. 


\begin{abstract}
The regulation by $\mathrm{Ca}^{2+}$ of $\mathrm{Ca}^{2+}$-permeable ion channels represents an important mechanism in the control of cell function. Polycystin-2 (PC2, TRPP2), a member of the TRP channel family (Transient Potential Receptor), is a $\mathrm{Ca}^{2+}$ permeable non-selective cation channel. Previous studies from our laboratory demonstrated that physiological concentrations of $\mathrm{Ca}^{2+}$ do not regulate in vitro translated PC2 ( $\mathrm{PC} 2$ iv $)$ channel activity. However, the issue as to $\mathrm{PC}^{\prime} \mathrm{s} \mathrm{Ca}^{2+}$ permeability and regulation remain ill-defined. In this study, we assessed $\mathrm{Ca}^{2+}$ transport by $\mathrm{PC} 2{ }_{\mathrm{iv}}$, in a lipid bilayer reconstitution system in the presence of a high $\mathrm{Ca}^{2+}$ gradient $\left(\mathrm{CaCl}_{2} 100 \mathrm{mM}\right.$ cis, $\mathrm{CaCl}_{2} 10 \mathrm{mM}$ trans). $\mathrm{PC} 2_{\mathrm{iv}}$ channel reconstitution was conducted in the presence of either 3:7 or 7:3 1-palmitoyl-2-oleoyl-choline (POPC) and ethanolamine (POPE) lipid mixtures. Reconstituted PC2 $2_{\text {iv }}$ showed spontaneous $\mathrm{Ca}^{2+}$ currents, in both lipid mixtures with a maximum conductance of $63 \pm 13$ $\mathrm{pS}(n=19)$ and $105 \mathrm{pS} \pm 9.8(n=9)$, respectively. In both cases, experimental data were best fitted with the Goldman-Hodgkin-Katz equation, showing a reversal potential $\left(\mathrm{V}_{\text {rev }} \sim-27 \mathrm{mV}\right)$ consistent with strict $\mathrm{Ca}^{2+}$ selectivity. The R742X mutated PC2 (PC2 $742 \mathrm{X}$ ), lacking the carboxy terminal domain of the channel showed no differences with wild type PC2. Interestingly, spontaneous $\mathrm{Ca}^{2+}$ current oscillations were observed whenever PC2-containing samples were reconstituted in the 3:7, but not 7:3 POPC:POPE lipid mixture. The amplitude and frequency of the oscillations were highly dependent on the applied voltage, the imposed $\mathrm{Ca}^{2+}$ gradient, and the presence of high $\mathrm{Ca}^{2+}$, which induced PC2 channel clustering as observed by atomic force microscopy (AFM). We also used the $\mathrm{QuB}$ suite to kinetically model the PC2 channel $\mathrm{Ca}^{2+}$ oscillations based on the presence of subconductance states in the channel. The encompassed data provide new evidence to support a high $\mathrm{Ca}^{2+}$ permeability by $\mathrm{PC} 2$, and a novel regulatory feedback mechanism dependent on the presence of $\mathrm{Ca}^{2+}$ and phospholipids on its function.
\end{abstract}

\title{
Statement of Significance
}

The regulation by $\mathrm{Ca}^{2+}$ of $\mathrm{Ca}^{2+}$-permeable ion channels represents an important mechanism in the control of cell function. The Transient Potential Receptor channel Polycystin-2 (TRPP2, PC2), is a $\mathrm{Ca}^{2+}$ permeable non-selective cation channel. $\mathrm{Ca}^{2+}$ transport by $\mathrm{PC} 2$ has largely been inferred by changes in reversal potential. This study provides experimental evidence on the $\mathrm{Ca}^{2+}$-transporting capabilities of PC2 in high $\mathrm{Ca}^{2+}$ that is modulated by lipids and generates a novel phenomenon of oscillatory currents by channel clustering and multiple subconductance behavior. PC2 can be self-regulated by feedback mechanisms, which are independent of external regulatory proteins. This oscillatory behavior, previously unknown for a single channel species, depend on the presence of $\mathrm{Ca}^{2+}$ interaction sites as have been postulated for the channel protein.

\section{Introduction}

Transient receptor potential (TRP) channels (1) are considered of fundamental importance for their contribution to the resting potential of cells, and a variety of cellular mechanisms in both excitable and non-excitable cells $(2,3)$. PC2 is a structural tetramer, whose activity is the summation of subconductance levels corresponding to a sequential activation of each of the four monomers $(4,5)$. Hetero-oligomerization such as that observed in TRPC1-PC2 hetero-complexes show distinct functional properties, including resistance to low $\mathrm{pH}$, and amiloride sensitivity, not observed in the homo-tetramers (5). PC2 is involved in the entry of $\mathrm{Ca}^{2+}$ into different epithelial tissues and organs $(4,6-9)$. The contribution of PC2 to cell signaling and $\mathrm{Ca}^{2+}$ homeostasis has been reported in different cellular compartments, including the primary cilium, intracellular $\mathrm{Ca}^{2+}$ reservoirs such as the endoplasmic reticulum (ER), and the plasma membrane $(7,10,11)$. Thus, PC2 plays an important role in $\mathrm{Ca}^{2+}$-mediated cell activation, and the dynamics of intracellular $\mathrm{Ca}^{2+}$ usually shows a complex space-time behavior. Many cell types respond to agonist stimulation with fluctuations in 
$\mathrm{Ca}^{2+}$ concentrations (12), which result from the periodic release of $\mathrm{Ca}^{2+}$ stored in intracellular compartments. In many cases, the oscillations are a signal of coded frequency that allows the cell to use $\mathrm{Ca}^{2+}$ as a second messenger. A known model of cytoplasmic $\mathrm{Ca}^{2+}$ oscillations is the two-reservoir model ("Two Pool", 13), based on the production of oscillations through the interaction between two $\mathrm{Ca}^{2+}$ reservoirs, one sensitive, and another insensitive to IP3 (sensitive to $\mathrm{Ca}^{2+}$ ). While a stimulus is present, a constant influx of $\mathrm{Ca}^{2+}$ from the insensitive IP3 reservoir occurs (14). Considering the fact that PC2 is present in the plasma membrane and its function is controlled by external $\mathrm{Ca}^{2+}$ concentrations (15), it is of interest to take a closer look at the $\mathrm{Ca}^{2+}$ permeability of this cation channel.

To date, $\mathrm{Ca}^{2+}$ transport by PC2 and homologues has been inferred by either change in reversal potential, and/or changes in ionic conductance at very high $\mathrm{Ca}^{2+}$ concentrations $(4,16)$. An intrinsic PC2 $\mathrm{Ca}^{2+}$ permeability at physiological $\mathrm{Ca}^{2+}$ was calculated for reconstituted human syncytiotrophoblast PC2 (PC2 ${ }_{\text {hst }}$ ) (16). In that study, a reduction of cis $\mathrm{Ca}^{2+}$ from $10 \mu \mathrm{M}$ to sub-nanomolar concentrations by addition of either EGTA or BAPTA, decreased the PC2-mediated $\mathrm{K}^{+}$currents. However, similar experiments conducted with in vitro translated PC2 (PC2 $\left.2_{\mathrm{iv}}\right)$ showed no changes in channel activity, suggesting that a $\mathrm{Ca}^{2+}$ microdomain surrounding the $\mathrm{PC} 2$ hst regulated the channel. This microdomain, which is absent in the in vitro translated channel protein, turned out to be comprised of $\mathrm{Ca}^{2+}$-sensitive cytoskeletal proteins that interact with the channel, and confer the regulation by $\mathrm{Ca}^{2+}(17)$. Ehrlich's group reported $\mathrm{Ca}^{2+}$-dependent conformational changes in the isolated carboxy terminus of PC2 (18), supporting the idea that the PC2 channel functionally interacts with $\mathrm{Ca}^{2+}$. It is currently unknown as to whether this phenomenon transmits any functional property to the channel complex. Our previous data were consistent with a scenario in which $\mathrm{Ca}^{2+}$ transport through PC2 was fed back by accessing intracellular cytoplasmic sites, thus maintaining channel function (16). Access to this information and the delivery of physiological concentrations of extracellular $\mathrm{Ca}^{2+}$ to the cytoplasmic domain allowed us to quantify the boundaries of $\mathrm{Ca}^{2+}$ permeability by PC2 from the relationship between the time necessary to reach PC2's channel half maximal activity $\left(t_{1 / 2}\right)$ and the external concentration of $\mathrm{Ca}^{2+}$. The flux coefficient $\left(\tau_{\mathrm{Ca}}\right)$ calculated in $\mathrm{KCl}$ and $\mathrm{CaCl}_{2}$ between $0.3 \mathrm{nM}$ and $1 \mathrm{mM}$, was $20 \mu$ s, reflecting the average time taken by $\mathrm{Ca}^{2+}$ to traverse the channel pore (trans/cis) to access and activate the $\mathrm{Ca}^{2+}$ regulatory sites. From the estimated $\tau_{\mathrm{Ca}}$ the calculated $\mathrm{Ca}^{2+}$ flux $\left(J_{\mathrm{Ca}}\right)$ through $\mathrm{PC} 2_{\mathrm{hst}}$ at physiologically relevant $\mathrm{Ca}^{2+}$ concentrations were in the order of $9.32 \times 10^{-20} \mathrm{moles} / \mathrm{s}$ to $1.48 \times 10^{-18} \mathrm{moles} / \mathrm{s}$, consistent with a PC2 $\mathrm{hst} \mathrm{Ca}^{2+}$ conductance from $\sim 0.15$ to $2.38 \mathrm{pS}$ in the presence of $1 \mathrm{mM}$ external $\mathrm{Ca}^{2+}(16)$. These flux values are high compared to those reported for most $\mathrm{Ca}^{2+}$-permeable channels under physiologically imposed electrochemical conditions (19). Our data were validated by means of electrodiffusional experiments obtained with $\mathrm{PC} 2{ }_{\mathrm{hst}}$ in the presence of a $\mathrm{K}^{+}$gradient and a high trans $\mathrm{Ca}^{2+}$ concentration $(90 \mathrm{mM})(16)$. We require direct measurements of electrodiffusional $\mathrm{Ca}^{2+}$ fluxes through PC2 to confirm these values.

Thus, in the present study we explored the $\mathrm{Ca}^{2+}$ permeability of PC2 in the presence of a $\mathrm{Ca}^{2+}$ chemical gradient and the absence of monovalent cations. We observed $\mathrm{Ca}^{2+}$ transport through $\mathrm{PC} 2$ in the isolated protein $\left(\mathrm{PC} 2_{\mathrm{iv}}\right)$. Interestingly, the $\mathrm{PC} 2_{\mathrm{iv}}$ maximal single channel conductance depended on the lipid mixture composition, showing as much as twice the channel permeability on the ratio of phospholipids. Another interesting finding was the presence of a novel $\mathrm{Ca}^{2+}$-induced functional clustering of PC2 channels, observed by AFM, to synchronize $\mathrm{Ca}^{2+}$ waves in the presence of a 3:7, but not 7:3 PC:PE lipid mixture. This is to our knowledge the first demonstration of $\mathrm{Ca}^{2+}$ oscillations in the presence of a single ion channel species. We constructed a theoretical four-state kinetic model of the PC2-mediated $\mathrm{Ca}^{2+}$ oscillations by with the QuB Software suite (20) that depended exclusively on the presence of subconductance states of the channel. The present study provides evidence on a novel regulatory mechanism of $\mathrm{Ca}^{2+}$ transport by $\mathrm{PC} 2$. 
bioRxiv preprint doi: https://doi.org/10.1101/2022.03.02.482677; this version posted March 3, 2022. The copyright holder for this preprint available under aCC-BY-NC-ND 4.0 International license.

Calcium Transport Mediated by PC2 - Velázquez et al 2022

\section{Methods}

Preparation of in vitro translated PC2. In vitro translated $\mathrm{PC} 2\left(\mathrm{PC} 2 \mathrm{iv}_{\mathrm{v}}\right)$ was prepared as previously reported (4). Briefly, the plasmid pGEM-PKD2 encoding PC2, was in vitro transcribed and translated with a reticulocyte lysate system TnT T7 (Promega, Fitchburg, WI) by incubation of plasmid DNA $(1 \mathrm{mg})$ and $50 \mathrm{~mL}$ of the reaction mixture for $90 \mathrm{~min}$ at $30^{\circ} \mathrm{C}$. The $\mathrm{PC} 2_{\mathrm{iv}}$ was introduced by dialysis into liposomes formed by a mixture of 1-palmitoyl-2-oleoyl-choline (POPC): 1-palmitoyl-2-oleoyl-ethanolamine (POPE) in a 7:3 ratio $(4,5)$. R742X truncated $\mathrm{PC} 2\left(\mathrm{PC} 2_{\mathrm{R} 742 \mathrm{X}}\right)$ lacking the carboxy terminal tail of the channel was prepared as previously described (21).

Preparation of proteoliposomes. PC2 was introduced into liposomes formed with a mixture of POPC:POPE, 7:3 for its subsequent reconstitution in lipid bilayers. Proteoliposomes containing PC2 were prepared with a 7:3 mixture of the polar lipids POPC $(10 \mathrm{mg} / \mathrm{ml}$, Avanti, Inc., AL) and $1.2 \mathrm{ml}$ POPE (25 mg/ml, Avanti, Inc., AL) to obtain a mixture of lipids $(40 \mathrm{mg})$ which was then dried with $\mathrm{N}_{2}$ and re-dissolved in n-decane. To the lipid mixture were added $4 \mathrm{ml}$ of cholate buffer $(25 \mathrm{mM}$ $\mathrm{Na}^{+}$-cholate, $150 \mathrm{mM} \mathrm{NaCl}, 0.1 \mathrm{mM}$ EDTA, $20 \mathrm{mM}$ HEPES, pH 7.2), which were sonicated in a bath for $45 \mathrm{~min}$. For the preparation of the proteoliposomes the PC2 $(1 \mathrm{mg} / \mathrm{ml})$ was diluted to 1 : 1.000 , and $1 \mathrm{ml}$ was added to $100 \mu \mathrm{l}$ of the lipid solution described above, and mixed with $0.2 \mathrm{ml}$ of $\mathrm{Na}^{+}$-cholate. The mixture was dialyzed against dialysis buffer $(150 \mathrm{mM} \mathrm{NaCl}, 0.1 \mathrm{mM}$ EDTA, 20 $\mathrm{mM}$ HEPES, $\mathrm{pH}$ 7.2) for 3 days at $4^{\circ} \mathrm{C}$ (with three buffer changes) (5).

Ion channel reconstitution. PC2 containing vesicles were inserted into a lipid bilayer reconstitution system as previously reported (4). For the present studies we used a $\mathrm{CaCl}_{2}$ chemical gradient (cis/trans 100:10 mM). Lipid mixtures were prepared from either 3:7 or 7:3 ratios, of synthetic POPC $(10 \mathrm{mg} / \mathrm{ml})$ and POPE $(10 \mathrm{mg} / \mathrm{ml})$ stock solutions (Avanti Polar Lipids, Birminham, AL), respectively. Lipid mixtures were dried with $\mathrm{N}_{2}$ and re-dissolved in $12 \mu \mathrm{l}$-decane, as described (22). Unless otherwise stated, the cis chamber contained a solution of $\mathrm{CaCl}_{2} 100 \mathrm{mM}$, and $\mathrm{HEPES}$ $10 \mathrm{mM}$, at $\mathrm{pH} 7.40$, while the trans side contained a similar solution with lower $\mathrm{CaCl}_{2}(10 \mathrm{mM})$, to create a $\mathrm{CaCl}_{2}$ chemical gradient. Wherever indicated, $\mathrm{PC} 2$ preparations were also reconstituted in the presence of either a biionic gradient $\mathrm{K}^{+} / \mathrm{Ca}^{2+}(\mathrm{KCl} 150$ cis and 10 trans $)$ or symmetrical $\mathrm{K}^{+}$ solution ( $\mathrm{KCl} 150, \mathrm{CaCl}_{2} 10 \mu \mathrm{M}$ cis and $\mathrm{KCl} 150, \mathrm{CaCl}_{2} 10 \mu \mathrm{M}$ trans).

PC2 channel inhibition. $\mathrm{PC}_{2}$ iv function was identified at the end of the experiment by inhibition with either trans (external) amiloride $(100 \mu \mathrm{M})$, or cis (cytoplasmic side) anti-PC2 antibody (1:1000, $10 \mu \mathrm{l}$, sc-25749, Santa Cruz Biotechnology), properties that also ensured its orientation in the reconstituted membrane.

Data acquisition and analysis. Single channel currents were obtained with a 10 G $\Omega$ feedback resistor PC501A patch-clamp amplifier (Warner Instruments, Hamden, CT), which was driven with the software pCLAMP 6.2 (4) from a personal computer. Output (voltage) signals were low-pass-filtered at $700 \mathrm{~Hz}(3 \mathrm{~dB})$ with an eight-pole, Bessel-type filter (Frequency Devices, Haverhill, MA). Single channel currents were further filtered for display purposes only. Unless otherwise stated, pClamp 10.0 (Axon Instruments, Foster City, CA), and Sigmaplot 11.0 (Jandel Scientific, Corte Madera, CA), were used for data analysis, and statistical analysis and graphics, respectively.

Atomic force microscopy. PC2 channel complexes were imaged with an ICON AFM attached to a Nano-Scope V controller (Bruker, Sta. Barbara, CA), as previously reported $(5,23)$. Unless otherwise stated, samples were scanned with oxide sharpened silicon-nitride tips (DNP-S, Bruker). BLMs were scanned in either tapping or contact mode, in liquid (Fig 2) with silicon nitride 
cantilevers with a spring constant of $0.06 \mathrm{~N} / \mathrm{m}$ and operating frequencies for the tapping mode of 8 $\mathrm{kHz}$ (tip radius estimated as $\sim 25 \mathrm{~nm}$ ). Scanning rates varied from 0.3 to $2 \mathrm{~Hz}$.

$\mathrm{Ca}^{2+}$ gradients and biionic conditions. Whenever indicated, addition of $\mathrm{Ca}^{2+}$ was performed by replacement of $200 \mu \mathrm{l}$ of solution of the trans hemi-chamber by $200 \mu \mathrm{CaCl}_{2} 1.0 \mathrm{M}$. Final concentration obtained in the trans compartment was $210 \mathrm{mM}$ in the bi-ionic gradient $(150 \mathrm{mM} \mathrm{KCl}$ cis, $\mathrm{CaCl}_{2} 10 \mathrm{mM}$ trans) and $200 \mathrm{mM}$ in symmetrical $\mathrm{K}^{+}(150 \mathrm{mM} \mathrm{KCl}$ cis, $\mathrm{KCl} 150 \mathrm{mM}$ trans $)$.

Kinetic Modeling of the PC2 Channel. Kinetic modeling of PC2 behavior was simulated with the QuB Classic software 2.0.0.13 (State University of New York, Buffalo, NY) (20). Kinetic models of the PC2 channel were simulated and exported to Clampfit 10.5 (Molecular Devices, LLC) for further analysis.

Goldman-Hodgkin-Katz and other field equations. The ionic conductance of the PC2 channel, was first determined by fitting experimental data from current to voltage relationships to the corrected Goldman-Hodgkin-Katz (GHK) current equation (24) such that:

$$
I=\sum_{S_{i}=1}^{n}\left(\frac{z_{i}^{2} F^{2} P_{i} V_{h}}{R T} \frac{\left[S_{i}^{+}\right]_{c i s}}{1-\exp ^{-\alpha}}+\frac{z_{i}^{2} F^{2} P_{i} V_{h}}{R T} \frac{\left[S_{i}^{+}\right]_{\text {trans }}}{1-\exp ^{\alpha}}\right)
$$

where $I$ is the single channel current, $\left[S_{i}^{+}\right]$is the concentration of ion $i$ in either (cis, trans) chamber, $V_{h}$ is the holding potential, and $\alpha=z_{i} F V_{h} / R T$. The constants $F, R$ and $T$ have their usual meaning. The original GHK approximation assumes a linear, or symmetric electric field profile $(25,26)$ across the membrane (constant field approximation), which is not always supported by channel behavior. In fact, early work by Hodgkin \& Keynes $(27,28)$ observed that the Ussing flux ratio, which also applies to unidirectional current ratios $I_{i} / I_{o}=\exp (\alpha)(28,29)$ can sometimes present ratios where the exponent containing the electric potential term is multiplied by factors higher than 1 . These higher ratios have been associated with multi-occupancy in the channel pore (26), where the number multiplying the exponential term represents the number of ions in the pore, and possibly other explanations such as electrical interactions in the pore, either between ions, or between an ionic species and the walls of the pore.

Statistical methods. Maximal $\mathrm{Ca}^{2+}$ conductance $\left(g_{\max }\right)$ for $\mathrm{PC}_{2}$ iv with either 3:7 or 7:3 POPC:POPE lipid mixture was obtained by linear regression, and comparisons were evaluated by Student $t$ test, with a significance of $\mathrm{p}<0.05$.

\section{Results}

$\mathrm{Ca}^{2+}$ transport through $P C 2_{i v}$. To study $\mathrm{Ca}^{2+}$ transport through $\mathrm{PC} 2_{\mathrm{iv}}$, the channel was reconstituted in a lipid bilayer system (see Materials \& Methods) in the presence of a $\mathrm{CaCl}_{2}$ chemical gradient (100 mM cis vs. $10 \mathrm{mM}$ trans), in either 3:7 or 7:3 POPC:POPE lipid mixtures. Holding potential differences between $\pm 200 \mathrm{mV}$ were applied. We observed spontaneous single channel $\mathrm{Ca}^{2+}$ currents $(n=105 / 360)$ in both lipid mixtures (Fig. 1a). Spontaneous single channel currents were most often elicited at high holding potentials $(>100 \mathrm{mV})$ and most frequently, several channel openings were observed at the same time, saturating the amplifier. Usually, we required application of holding potentials as high as $200 \mathrm{mV}$ to elicit ion channel transitions that could be recorded at lower holding potentials afterwards. Current-to-voltage relationships for each lipid mixture revealed a $V_{\text {rev }}$ expected for $\mathrm{Ca}^{2+}$ permeation (Theoretical $V^{C a}{ }_{r e v}$ of $-29.5 \mathrm{mV}$ ) (Fig 1b). Data were fitted with the corrected GHK equation (Eq. 2) in the presence of either, 7:3 POPC: POPE, (Fig. 1b Left), or 3:7 
(Fig. 1b Right) lipid compositions. In the presence of the 7:3 POPC: POPE mixture, the maximum $\mathrm{Ca}^{2+}$ conductance $\left(g_{\max }\right)$ was $104.4 \pm 9.8 \mathrm{pS}(n=9)$, with a $V_{r e v}$ was $-28 \mathrm{mV}$, most consistent with a $\mathrm{Ca}^{2+}$ permeability $\left(P_{C a}\right)$ of $6.94 \times 10^{-14} \mathrm{~cm}^{3} \mathrm{~s}^{-1}$. In the presence of the 3:7 POPC: POPE lipid mixture, however, $g_{\max }$ was $78.8 \pm 7.1 \mathrm{pS}(n=19)$, with a $P_{C a}$ of $1.18 \times 10^{-14} \mathrm{~cm}^{3} \mathrm{~s}^{-1}$, thus $83 \%$ lower than that with the other lipid mixture $(\mathrm{p}<0.05)$, and a $V_{\text {rev }}$ of $-31 \mathrm{mV}$.

$\mathrm{Ca}^{2+}$ transport through truncated $P C 2_{R 742 X} . \mathrm{Ca}^{2+}$ transport was also studied through the ADPKD-causing truncated $\mathrm{PC} 2_{\mathrm{R} 742 \mathrm{X}}$. This mutation lacks the cytoplasmic carboxy terminal tail of PC2. PC2 $2_{\mathrm{R} 742 \mathrm{X}}$ was reconstituted using the 3:7 POPC:POPE lipid mixture in the presence of a $\mathrm{Ca}^{2+}$ gradient similar to that applied to wild type $\mathrm{PC}_{2}$ iv. Spontaneous $\mathrm{Ca}^{2+}$ currents were observed $(n=$ 30/41), with a similar $\mathrm{Ca}^{2+}$ conductance to that of the wild type PC2 iv (Fig. 1b Right, gray symbols). It is important to note that was very difficult to obtain single channel tracings from $\mathrm{PC} 2 \mathrm{R} 742 \mathrm{X}$ reconstituted in $\mathrm{Ca}^{2+}$ chemical gradient.

a.
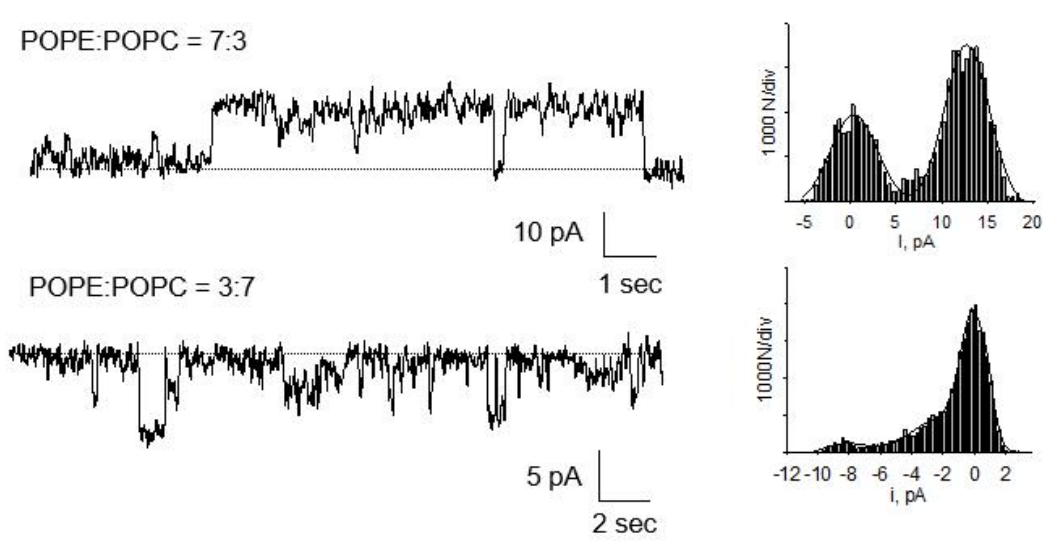

b.
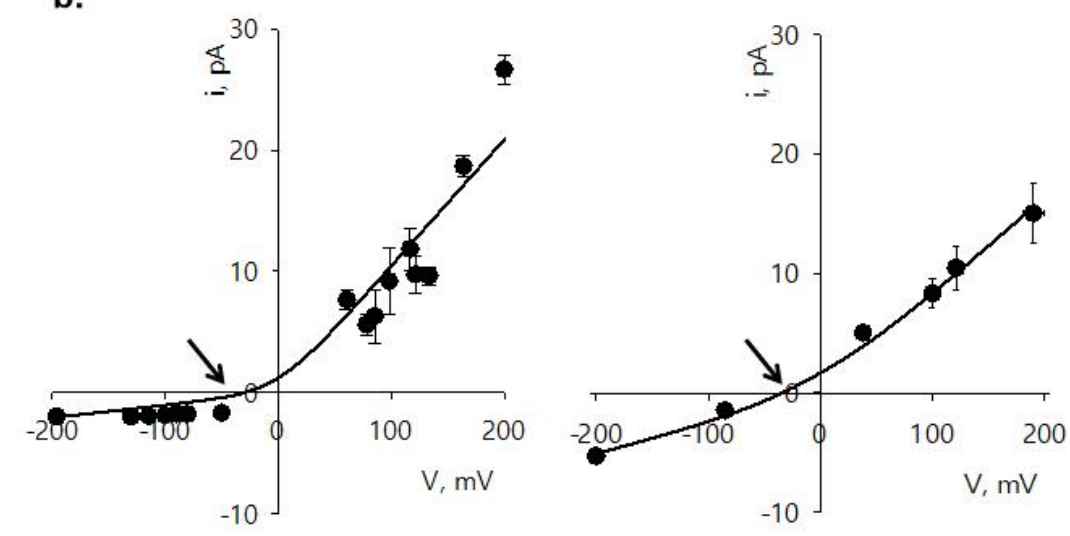

Fig. 1: $\mathrm{Ca}^{2+}$ transport through $P C 2_{i v}$ a. Left. Representative $P C 2_{i v}$ single channel $\mathrm{Ca}^{2+}$ currents. The channel was reconstituted in a lipid bilayer system in the presence of a $\mathrm{Ca}^{2+}$ gradient and either a POPE:POPC 7:3 (100 mV) or 3:7 (-200 mV) lipid mixture. Representative tracings from $n=$ 105/360. The closed level is indicated by the dotted line. Right. All-point amplitude histogram. Black line represents the best fit for two Gaussians, corresponding to the closed and open levels. b. 
Current to voltage relationships obtained with either 7:3 (Left) or 3:7 (Right) POPC: POPE lipid mixtures fitted with the GHK model (solid line). Gray symbols represents current-to-voltage relationship for $\mathrm{PC} 2 \mathrm{R} 742 \mathrm{X}$.

Current oscillations of reconstituted $P C 2_{i v}$ in the presence of a $\mathrm{Ca}^{2+}$ gradient. Most often several channel openings were simultaneously observed after reconstitution of $\mathrm{PC}_{2}$ iv in a $\mathrm{Ca}^{2+}$ gradient (cis $100 \mathrm{mM}$ vs. trans $10 \mathrm{mM}$ ). Under these conditions, an interesting phenomenon was the observation of current oscillations (Fig. $2 \mathrm{a} \& \mathrm{~b}$ ). This electrical phenomenon was present in experiments where PC2 $2_{\text {iv }}$ was reconstituted in the 3:7 POPC:POPE lipid mixture $(n=29 / 139)$. Reconstitution of PC 2 iv in the 7:3 POPC:POPE lipid mixture, showed single channel activity in 16/96 experiments with no current oscillations. Also interesting, reconstitution of $\mathrm{PC} 2_{\mathrm{R} 472 \mathrm{X}}$ under similar conditions, showed no current oscillations in the 3:7 POPC:POPE lipidic mixture $(n=0 / 41)$.

The oscillatory current amplitude (in pA) depended on the applied voltage (Fig. 3a Top), being greater at higher potentials. The oscillation frequency $(\mathrm{Hz})$ did not respond linearly with respect to the holding potential (Fig. 2a Bottom), but instead according to the phenomenological equation,

$$
f(H z)=a \times \exp \left[-0.5\left(\frac{V_{h}-V_{0}}{b}\right)^{2}\right]
$$

where $f$ is the frequency in $\mathrm{Hz}, a$ and $b$ are constants, $V_{h}$ is the holding potential (in $\mathrm{mV}$ ) and $V_{0}$ is the peak voltage (also in $\mathrm{mV}$ ).
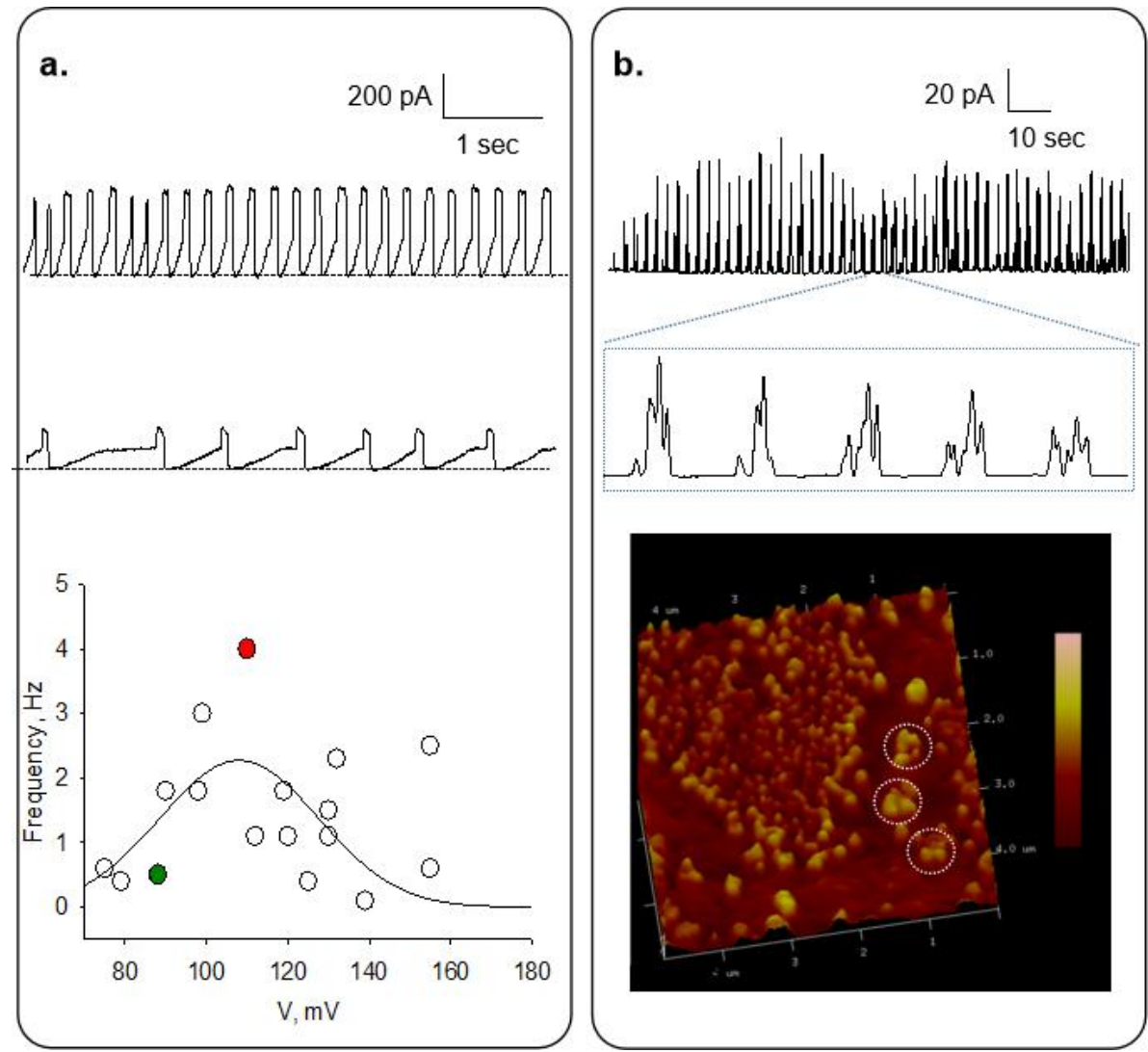
Fig. 2: $P C 2_{i v} \mathrm{Ca}^{2+}$ current oscillations in a $\mathrm{CaCl}_{2}$ gradient. a. Top and Middle. Representative electric oscillations in the presence of $\mathrm{CaCl}_{2} 100 \mathrm{mM}$ cis and $\mathrm{CaCl}_{2} 10 \mathrm{mM}$ trans reconstituted in the presence of the 3:7 POPC: POPE lipid mixture. Zero current level is indicated by the dashed line. Bottom. Frequency of oscillations $(\mathrm{Hz})$ vs. voltage $(\mathrm{mV})$. Data were adjusted with the phenomenological equation (Eq. 3) (black curve). Red and green dots are the values obtained from the Top an Middle tracings. b. Electrical recording obtained with the AFM connected to a lipid bilayer system (23). Scanning shows the PC2 channel clustering in high $\mathrm{Ca}^{2+}$.

PC2 channel clustering and $\mathrm{Ca}^{2+}$ oscillations. To further explore whether the lipid composition could be implicated in generating the $\mathrm{Ca}^{2+}$ oscillations by PC2, channel-containing liposomes were flattened and scanned in a system we recently developed to simultaneously assess single channel currents and topological features of the ion channels (23). The oscillatory phenomenon occurred when $\mathrm{PC} 2{ }_{\mathrm{iv}}$ clustering of various channel complexes was observed (Fig. 2b Bottom).

Current oscillations of reconstituted $\mathrm{PC}_{2}$ iv the presence of $\mathrm{Ca}^{2+}$ gradient and other ions. To determine whether the $\mathrm{PC}_{2}$ iv current oscillations were caused by $\mathrm{Ca}^{2+}$ transport, saline solutions in the reconstitution chamber were substituted with other salts. We first replaced the cis solution with $150 \mathrm{mM} \mathrm{KCl} . \mathrm{PC} 2_{\text {iv }}$ was reconstituted using the 3:7 POPC:POPE lipid mixture in this new biionic gradient condition (cis $150 \mathrm{mM} \mathrm{KCl}, 10 \mu \mathrm{M} \mathrm{CaCl}_{2}$ and trans $10 \mathrm{mM} \mathrm{CaCl}_{2}$ ). No oscillations were observed despite the fact that channel activity was present under these conditions. Subsequently, 200 $\mu \mathrm{l}$ of the trans solution was replaced by $200 \mu \mathrm{l}$ of $1.0 \mathrm{M} \mathrm{CaCl}_{2}$, obtaining a final trans concentration of $210 \mathrm{mM} \mathrm{CaCl}_{2}$. With the increase of trans $\mathrm{Ca}^{2+}$, oscillations were again observed $(n=10 / 36$, Fig. 3a Top). However, oscillations were different in shape from those observed in the presence of a $\mathrm{Ca}^{2+}$ gradient alone (see Fig. 2 for comparison). Because the oscillatory phenomenon was observed even in the absence of high cis $\mathrm{Ca}^{2+}$, we further evaluated if replacement of the trans solution $(10 \mathrm{mM}$ $\left.\mathrm{CaCl}_{2}\right)$ affected the appearance of the oscillations. PC2 iv channels were placed on the 3:7 lipid mixture under symmetrical $150 \mathrm{mM} \mathrm{KCl}$ and $10 \mu \mathrm{M} \mathrm{CaCl}_{2}$ Conditions. Although channel activity was observed, no ionic oscillations were elicited (data not shown). Subsequently, $\mathrm{KCl}$ was replaced by $\mathrm{CaCl}_{2}$ to the trans solution, obtaining a final trans concentration of $120 \mathrm{mM} \mathrm{KCl}$ and $200 \mathrm{mM}$ $\mathrm{CaCl}_{2}$. With the increase in trans $\mathrm{Ca}^{2+}$, current oscillations were again observed $(n=4 / 14$, Fig. 3a Bottom). Therefore, the amplitude, frequency and shape of the current oscillations through $\mathrm{PC} 2_{\mathrm{iv}}$ depended on the imposed ionic gradients, the applied holding potential, and the presence of high $\mathrm{Ca}^{2+}$ in the hemi-chambers.

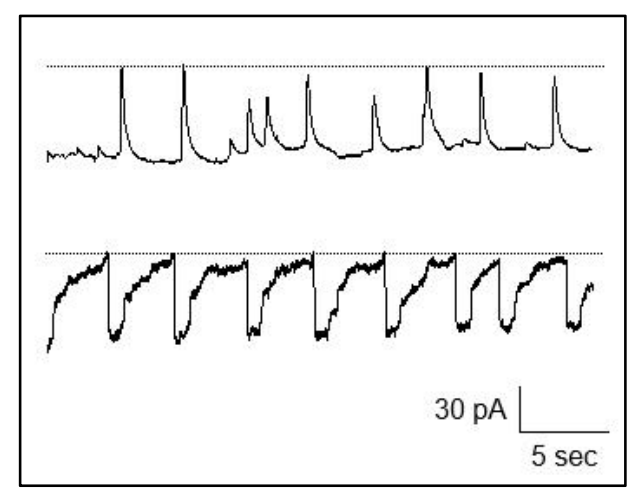

Fig. 3: $P C 2_{i v}$ current oscillations under several ionic conditions. Representative tracings of $P C 2_{i v}$ electric oscillations in the presence of either $\mathrm{KCl} 150 \mathrm{mM}, 10 \mu \mathrm{MCaCl} \mathrm{Cis}_{2}, 210 \mathrm{mM}$ trans $\mathrm{CaCl}_{2}$ (Top) or $\mathrm{KCl} 150 \mathrm{mM}, 10 \mu \mathrm{M} \mathrm{CaCl}$ cis; $120 \mathrm{mM} \mathrm{KCl,} \mathrm{CaCl} 2200 \mathrm{mM}$ trans (Bottom) reconstituted in a 3:7 POPC:POPE lipid mixture. Zero current level is indicated by the dotted line. 
Calcium Transport Mediated by PC2 - Velázquez et al 2022

Table 1. Kinetic Parameters for the five substate PC2 model

\begin{tabular}{c|c|c|c|c}
\hline Substate & Current, pA & SD, pA & $\begin{array}{c}\text { Transition constant to } \\
\text { previous level, } \mathbf{s}^{\mathbf{1}}\end{array}$ & $\begin{array}{c}\text { Transition constant to next } \\
\text { level, } \mathbf{s}^{\mathbf{1}} \\
\mathbf{C}\end{array}$ \\
0 & 0.01 & - & 1000 \\
$\mathbf{O}_{\mathbf{1}}$ & 1 & 0.05 & 500 & 1000 \\
$\mathbf{O}_{2}$ & 2 & 0.05 & 500 & 1000 \\
$\mathbf{O}_{3}$ & 3 & 0.05 & 250 & 1000 \\
$\mathbf{O}_{4}$ & 4 & 0.05 & 100 & - \\
\hline
\end{tabular}

Kinetic model of $P C 2$ channel simulated in $Q u B$. From the results of the oscillatory currents elicited by reconstituted PC2 in the various preparations, a kinetic model was sought that could explain the oscillatory behavior of $\mathrm{PC} 2$ iv. Our previous studies demonstrated that both $\mathrm{PC} 2{ }_{\mathrm{hst}}$ and $\mathrm{PC} 2$ iv display four subconductance states of equal amplitude in a $\mathrm{K}^{+}$gradient $(150 \mathrm{mM}$ cis and $15 \mathrm{mM}$ trans), consistent with intrinsic characteristics of the ion channel $(4,5)$. Based on these findings, we designed a kinetic model of the PC2 channel in the QuB Classic suite (Open Ware, New York State Univ, Buffalo, NY). This software to design ion channel behavior is based on Markov processes, where the transitions between different substates of the channel are probabilities, such that changes per unit time of the state's probability will only depend on the event in progress and not on past events (no memory). The PC2 kinetic model consisted of five states, a closed (C) state, and four conductive (open, O) substates $\mathrm{O}_{1}-\mathrm{O}_{4}$ (Fig. 4a) where each of the states is characterized by increasing amplitude, and each transition by its speed constants (see Table 1). The simulations were run with $n=1$ (Fig. 4b), and the simulation time was 9 seconds. This kinetic model of PC2 was the one that more closely approximated the previously reported data from our laboratory (Fig. $4 \mathrm{~b}$, see Fig. 1, in 5), and reproduced the mean closed time and the four sub-conductance states of the PC $2_{\mathrm{hST}}$ channel. 


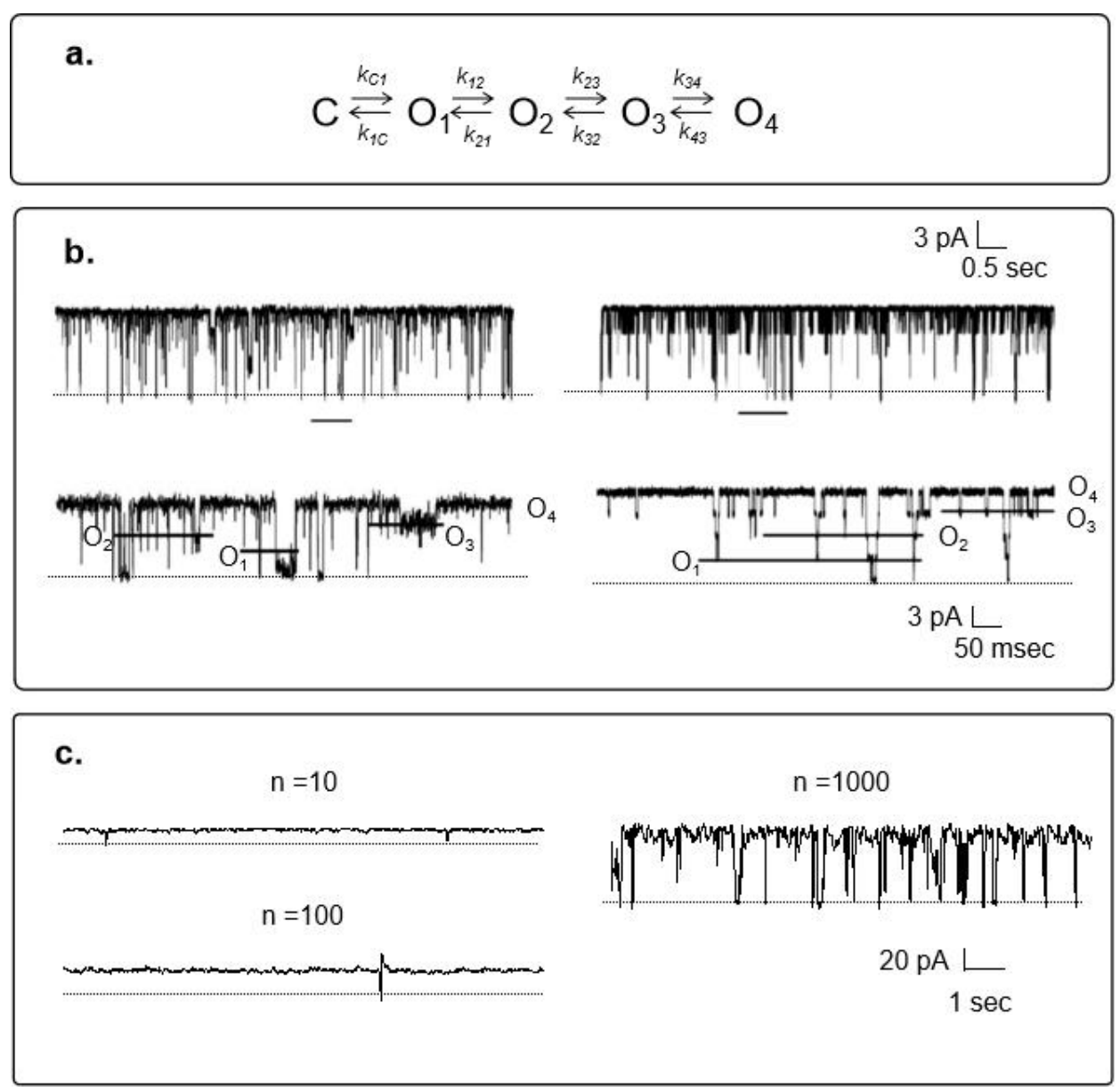

Fig. 4: QuB simulation of PC2 channel behavior. a. Kinetic model used in the QuB simulation of $P C 2-m e d i a t e d K^{+}$currents. b. Left. $P C 2_{\text {hst }}$ single channel currents in a $\mathrm{K}^{+}$gradient $(150 \mathrm{mM} \mathrm{cis} \mathrm{KCl}$, $15 \mathrm{mM}$ trans) and a holding potential of $60 \mathrm{mV}$ as originally reported (5). Tracing below is an expanded region indicated at the horizontal line, where the four substates $\left(\mathrm{O}_{1}-\mathrm{O}_{4}\right)$ of the channel are indicated by the horizontal lines. Right. Simulated kinetic model of PC2 in QuB. Horizontal lines indicate the different subconductance levels $\left(\mathrm{O}_{1}-\mathrm{O}_{4}\right)$ of the simulated tracing. Dotted lines indicate zero current level. c. Simulation with $n=10,100$ and 1000 channel units. Dotted line indicates zero current level.

Table 2. Transition constants of the four substate PC2 kinetic model

\begin{tabular}{c|c|c|c|c}
\hline Substate & Current, pA & SD, pA & $\begin{array}{c}\text { Transition constant to } \\
\text { previous level, } \text { sec }^{-1}\end{array}$ & $\begin{array}{c}\text { Transition constant to next } \\
\text { level, } \text { sec }^{\mathbf{1}}\end{array}$ \\
\hline $\mathbf{C}$ & 0 & 0.10 & - & 10000 \\
$\mathbf{O}_{\mathbf{1}}$ & 10 & 0.15 & 1 & 10000 \\
$\mathbf{O}_{2}$ & 10 & 0.15 & 100 & 1 \\
$\mathbf{O}_{3}$ & 10 & 0.15 & 1000 & - \\
\hline
\end{tabular}

Simulation of PC2 channel oscillations with QuB. To determine whether the activity of the PC2 $2_{\mathrm{QuB}}$ channels (PC2 reconstructed by QuB) kinetically reproduced the oscillations observed under $\mathrm{Ca}^{2+}$ gradients and biionic conditions $\left(\mathrm{K}^{+}\right.$and $\left.\mathrm{Ca}^{2+}\right)$, several channels were idealized with the same parameters. From 2 to 100 identical channels were explored with the same Markovian 
characteristics. However, the simulation failed to reproduce the current oscillations, even by increasing channel number to $n=1000$ (Fig. 4c). This simulated model responded to the expected stochastic model.
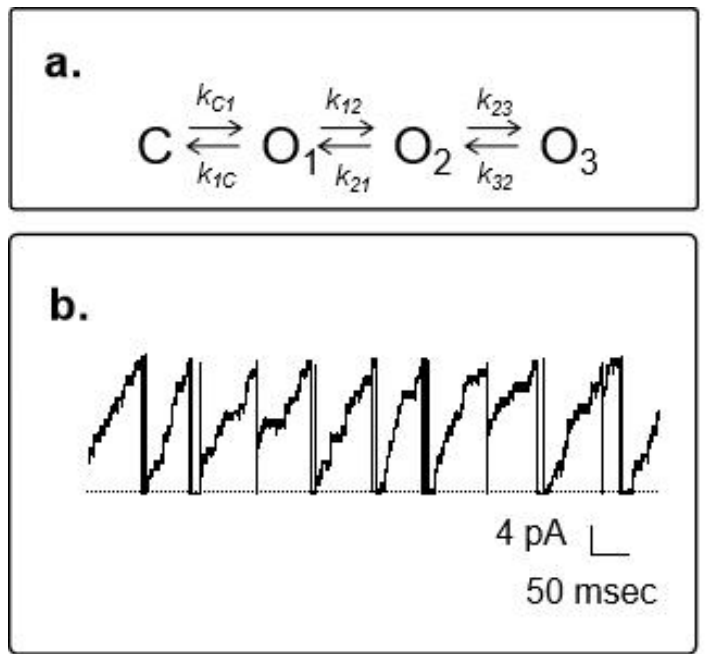

c.
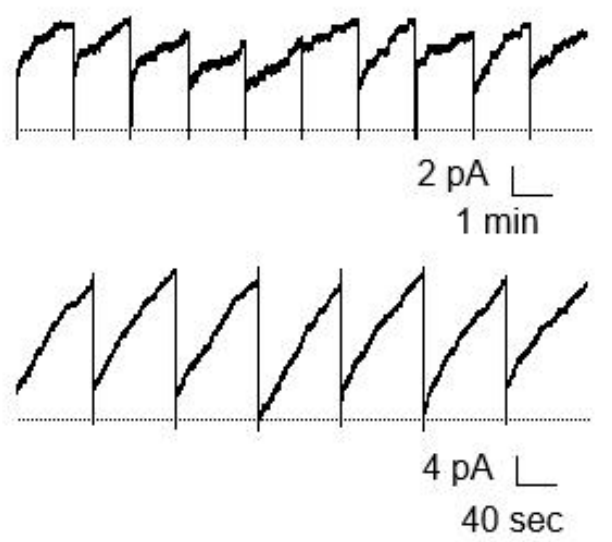

Fig. 5: QuB simulation model of PC2-mediated current oscillations. a. Kinetic model of PC2 that supports current oscillations. b. Representative current oscillations simulated with 100 channels with $10 \mathrm{pA}$ current amplitude. $\boldsymbol{c}$. Simulation with 100 and 1000 channels (Top and Bottom, respectively) of the same kinetic model, with PC2 channels whose open state amplitude is $1 \mathrm{pA}$.

The experimentally-observed PC2-mediated $\mathrm{Ca}^{2+}$ current oscillations showed large amplitudes that depended on the imposed gradient. In all cases, the amplitude was greater than $50 \mathrm{pA}$, meaning that oscillations required the synchronous activity of several open channels. During oscillations it was not possible to visualize the four conductive states of the channel. All the channels must be completely opened at the $g_{\max }$ level, and closed in a synchronized manner (see Figs. $2 \& 3$ ). The previously proposed stochastic model, which reproduced the PC2 single channel currents in a $\mathrm{K}^{+}$ gradient, failed to reproduce the multiple channel oscillations, therefore a mechanism was further sought that could better approximate the experimental data. Thus, another kinetic model of the channel was designed, which was called a PC2 ${ }_{\text {iv }}$ oscillatory model (Fig. 5a), which consisted of a closed state and three open states of equal amplitude (see Table 2). The rate constants for each transition state were modified such that when changing the residence time, the behavior of the channel simulated a cooperative phenomenon (Table 2). Thus, values for the transition constants were chosen such that they reproduced a rapid opening of the channel to its $g_{\max }$ level, and then also quickly fell to the closed state. These channel transitions generated an oscillatory behavior.

A representative plot of current oscillations in symmetrical $\mathrm{K}^{+}$was observed where the kinetic model partially reproduced the periodic behavior of the PC2 channel when the simulation ran with $n$ $=100$ channels (Fig. 5b). Simulations of the PC2 channel with the same kinetic model, but a modified conductance to a tenth of the original conductance, i.e. $1 \mathrm{pA}$ maximum amplitude, also managed to reproduce the oscillatory behavior when running simulations with 100 and 1000 channels (Fig. 5c). Thus, the oscillatory behavior of the PC2 channel currents largely depends on the kinetic changes of the channel, and not to changes in its conductance. Amplification of $\mathrm{PC} 2 \mathrm{Ca}^{2+}$ currents in a $\mathrm{Ca}^{2+}$ gradient and the $\mathrm{QuB}$ simulated oscillations shows the staircase behavior in both cases (Fig. 6 a \& b) 


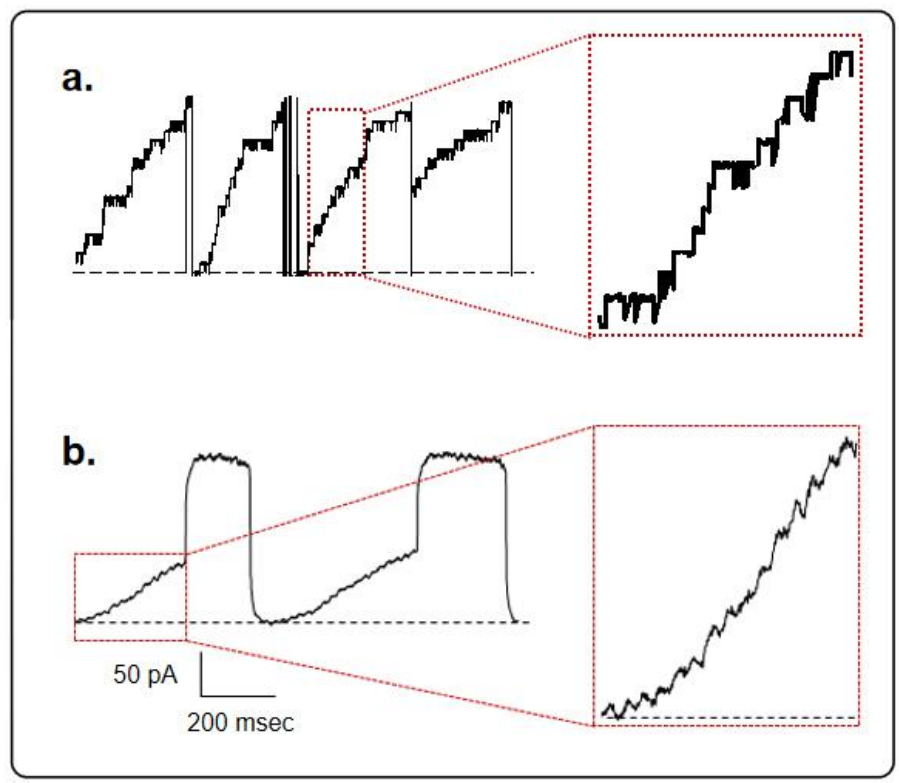

Fig. 6: Staircase amplification of $P C 2 \mathrm{Ca}^{2+}$ currents. a. Left. QuB simulated oscillations with a 100, 1 A channels. Right. Amplification of $\mathrm{PC}_{\mathrm{ptv}} \mathrm{Ca}^{2+}$ currents. b. Left. Representative tracing of PC2 current oscillations in a $\mathrm{Ca}^{2+}$ gradient, and its corresponding amplification (Right). Holding potential $117 \mathrm{mV}$. The inset shows unitary jumps.

\section{Discussion}

The regulation by $\mathrm{Ca}^{2+}$ of $\mathrm{Ca}^{2+}$-permeable ion channels represents an important mechanism in the control of all cellular function. The carboxyl terminus of the epithelial $\mathrm{Ca}^{2+}$ channel $\mathrm{ECaC} 1$, for example, is involved in $\mathrm{Ca}^{2+}$ dependent inactivation (30). PC2, a member of the TRP channel superfamily, is a high conductance, $\mathrm{Ca}^{2+}$-permeable non-selective cation channel, whose dysfunction causes ADPKD. The study of $\mathrm{Ca}^{2+}$ transport and channel regulation by $\mathrm{Ca}^{2+}$ through this and other channels expressed in non-excitable cells, is of relevance, because as a whole, it represents one of the initial steps in signaling mechanisms of the primary cilium and other cellular compartments (31).

The present study evaluated $\mathrm{Ca}^{2+}$ transport by PC2 at high $\mathrm{Ca}^{2+}$ concentrations. Reconstituted $\mathrm{PC} 2_{\text {iv }}$ in a $\mathrm{Ca}^{2+}$ gradient elicited spontaneous $\mathrm{Ca}^{2+}$ currents in $64 \%$ of the cases $(n=105 / 360)$. PC2 channel reconstitution in a BLM system provided us the means to determine that the presence of different phospholipid compositions, namely, POPC: POPE, 3:7 and 7:3, in the membrane, affected the PC2 mediated $\mathrm{Ca}^{2+}$ currents in the isolated protein ( $\mathrm{PC} 2$ iv). Significant differences were observed in the maximum $\mathrm{Ca}^{2+}$ conductance, which was almost twice as large in the 7:3 POPC: POPE ratio, as compared to the reverse 3:7 ratio; thus, suggesting an important effect of the lipidic environment on channel conductance. Interestingly, the estimated $\mathrm{V}_{\text {rev }}$ in both conditions was unaffected by the lipidic environment, and consistent with the same high cationic perm-selectivity. The truncated $\mathrm{PC} 2_{\mathrm{R} 742 \mathrm{X}}$ channel, also displayed similar $\mathrm{Ca}^{2+}$ channel activity, suggesting that the absence of the carboxy-terminal tail of the channel does not affect $\mathrm{Ca}^{2+}$ transport by PC2. However, PC2 $2_{\mathrm{R} 742 \mathrm{X}}$ channel was more difficult to reconstitute in a BLM and obtain $\mathrm{Ca}^{2+}$ currents, probably because high $\mathrm{Ca}^{2+}$ affect the stability of the interaction between the subunits that form the channel pore. Moreover, no oscillations were observed with this sample. 
A surprising observation while studying $\mathrm{PC}_{\mathrm{iv}} \mathrm{Ca}^{2+}$ transport in $\mathrm{Ca}^{2+}$ gradients was the presence of ionic current oscillations. This oscillatory behavior was observed in $21 \%(n=29 / 139)$ of the experiments where PC2 $2_{\text {iv }}$ was reconstituted in the presence of the 3:7 POPC: POPE lipid mixture, but not the 7:3 lipid mixtures. Neither were oscillations observed with truncated $\mathrm{PC} 2_{\mathrm{R} 742 \mathrm{X}}$, suggesting that the carboxy terminal end of the protein might play a role in the phenomenon, most likely by contributing to the expected ion channel assemblies. PC2 channel clustering on the oscillatory ion channel current phenomenon was further confirmed by current recordings of AFM scanned BLMs, with the technique we recently reported (23). The amplitude and intrinsic frequency of the current oscillations depended on various parameters, including the applied holding potential, the imposed ionic gradient, and the presence of high $\mathrm{Ca}^{2+}$. This interesting phenomenon, likely generated by the clustering of a single ion channel species in the absence of extrinsic regulatory proteins, requires a feedback mechanism, as expected from other $\mathrm{Ca}^{2+}$ chemical oscillators, and in this case, actually depended upon the transport kinetics of the channel that is controlled by the same transported $\mathrm{Ca}^{2+}$. This hypothesis was confirmed by simulations of multistep PC2 channel behavior in the $\mathrm{QuB}$ program, where we observed that the simple stochastic behavior of $\mathrm{PC}_{2}$ iv would respond as a quasi-deterministic phenomenon, as observed in stochastic resonance (32).

The data in this study provides novel evidence, confirming the $\mathrm{Ca}^{2+}$-transporting capabilities of PC2, further supporting the contention that the channel could be self-regulated by means of feedback mechanisms, which are independent of external regulatory proteins, as previously observed in our laboratory (17). This oscillatory behavior, previously unknown for single channel species, would likely depend on the presence of $\mathrm{Ca}^{2+}$ interaction sites as have been postulated for the carboxy terminus of the channel protein (18). The same region in the PC2-like, polycystin-L (33), however, seems to convey the same effect. Our results refute the apparent absence of regulatory sites in the channel protein, which is unapparent at low $\mathrm{Ca}^{2+}$ concentrations. The oscillations in the $\mathrm{Ca}^{2+}$ currents of the isolated protein ( $\mathrm{PC}_{\text {iv }}$ ) would require interaction sites, as a feedback mechanism that generates the oscillations, where the kinetics of the channel would be controlled by the transported ion. This may involve a coupling of the ion to intracellular sites of the same channel or, potentially, "structural" phospholipids, or charges that control the probability of the open state. Since the oscillatory electrical responses in "non-excitable" cellular models would be associated with oscillations of intracellular $\mathrm{Ca}^{2+}(13,14)$, the data in this study, suggest a minimalist model where the voltage sensitivity of PC2 would be conferred by $\mathrm{Ca}^{2+}$-dependent conformational changes. From these findings, we have been able to confirm the importance of $\mathrm{Ca}^{2+}$ permeability by $\mathrm{PC} 2$, and its regulation by the ion, in a behavior that is comparatively similar to voltage-activated $\mathrm{Ca}^{2+}$ channels. Future studies will be required to further explore the possible feedback mechanisms that help determine whether the presence of the oscillatory phenomenon observed with the isolated $\mathrm{PC} 2 \mathrm{iv}$ protein is also possible in different cellular environments.

\section{Author contributions}

IFV carried out all experimental procedures. IFV and MdRC conducted the analysis of the experimental data and prepared Figures and Tables. HFC and MdRC designed all the experiments and wrote the main manuscript. All authors reviewed the manuscript.

\section{Declaration of interests}

The authors declare no competing financial interests.

\section{Acknowledgements}


This study was funded by Ministerio de Ciencia, Tecnología e Innovación, Argentina, FONCyT, PICT $2012 \mathrm{~N}^{\circ} 1559$ (HC).

\section{References}

1. Montell, C. 2001. Physiology, phylogeny, and functions of the TRP superfamily of cation channels. Sci STKE. 90: re1.

2. Emmons, S.W., and S. Somlo. 1999. Signal transduction. Mating, channels and kidney cysts. Nature. 401(6751): 339-340.

3. Minke, B. 2010. The history of the Drosophila TRP channel: the birth of a new channel superfamily. J. Neurogenet. 24(4): 216-233.

4. González-Perrett, S., Kim, K., Ibarra, C., Damiano, A.E., Zotta, E., Batelli, M., Harris, P.C., Reisin, I.L., Arnaout, M.A., and H.F. Cantiello. 2001. Polycystin-2, the protein mutated in autosomal dominant polycystic kidney disease (ADPKD), is a $\mathrm{Ca}^{2+}$ permeable nonselective cation channel. Proc. Natl. Acad. Sci. USA. 98(3): 1182-1187.

5. Zhang, P., Luo, Y., Chasan, B., González-Perrett, S., Montalbetti, N., Timpanaro, G.A., Cantero, M.R., Ramos, A.J., Goldmann, W.H., Zhou, J., and H.F. Cantiello. 2009. The multimeric structure of polycystin-2 (TRPP2): structural-functional correlates of homo- and hetero-multimers with TRPC1. Hum. Mol Genet. 18(7): 1238-1251.

6. Luo, Y., Vassilev, P.M., Li, X., Kawanabe, Y., and J. Zhou. 2003. Native polycystin 2 functions as a plasma membrane $\mathrm{Ca}^{2+}$-permeable cation channel in renal epithelia. Mol Cell Biol. 23(7): 2600-2607.

7. Tsiokas, L. 2009. Function and regulation of TRPP2 at the plasma membrane. Am. J. Physiol. 297: F1-F9.

8. Narayanan, D., Bulley, S., Leo, M.D., Burris, S.K., Gabrick, K.S., Boop, F.A., and J.H. Jaggar. 2013. Smooth muscle cell transient receptor potential polycystin-2 (TRPP2) channels contribute to the myogenic response in cerebral arteries. J. Physiol. 591: 5031-5046,

9. Zhao, R., Zhou, M., Li, J., Wang, X., Su, K., Hu, J., Ye, Y., Zhu, J., Zhang, G., Wang,, K., Du, J., Wang, L.C., and B. Shen. 2015. Increased TRPP2 expression in vascular smooth muscle cells from high-salt intake hypertensive rats: The crucial role in vascular dysfunction. Mol. Nutr. Food Res. 59: 365-372.

10. Koulen, P., Cai, Y., Geng, L., Maeda, Y., Nishimura, S., Witzgall, R., Ehrlich, B.E., and S. Somlo. 2002. Polycystin-2 is an intracellular calcium release channel. Nat. Cell Biol. 4: 191-197.

11. Zhou, J. 2009. Polycystins and primary cilia: primers for cell cycle progression. Annu. Rev. Physiol. 71: 83-113.

12. Berridge, M.J. 1993. Inositol trisphosphate and calcium signaling. Nature 361(6410): 315-25.

13. Berridge, M.J. 1991. Cytoplasmic calcium oscillations: A two pool model. Cell calcium. 12: 63-72. 
14. Goldbeter, A., Genevieve, D., and M.J. Berridge. 1990. Minimal model for signal-induced $\mathrm{Ca}^{2+}$ oscillations and for their frequency encoding through protein phosphorylation. Proc. Natl. Acad. Sci. USA 87: 1461-1465.

15. Dai, X.Q., Perez, P.L., Soria, G., Scarinci, N., Smoler, M., Morsucci, D.C., Suzuki, K., Cantero, M.R., and H.F. Cantiello. 2017. External $\mathrm{Ca}^{2+}$ regulates polycystin-2 (TRPP2) cation currents in LLC-PK1 renal epithelial cells. Exp Cell Res. 350(1):50-61.

16. Cantero, M.R., and H.F. Cantiello. 2013. Calcium transport and local pool regulate polycystin-2 (TRPP2) function in human syncytiotrophoblast. Biophys. J. 105: 365-375.

17. Cantero, M.R., and H.F. Cantiello. 2015. Polycystin-2 (TRPP2) regulation by $\mathrm{Ca}^{2+}$ is effected and functionally diversified by direct interaction with different actin-binding proteins. Biophys. J. 108: 2191-2200.

18. Ćelić, A.S., Petri, E.T., Benbow, J., Hodsdon, M.E., Ehrlich, B.E., and T.J. Boggon. 2012. Calcium-induced conformational changes in C-terminal tail of polycystin-2 are necessary for channel gating. J. Biol. Chem. 287(21): 17232-17240.

19. Demuro, A., and I. Parker. 2006. Imaging single-channel calcium microdomains. Cell calcium 40: 413-422.

20. Qin, F., Auerbach, A., and F. Sachs. 1996. Estimating single-channel kinetic parameters from idealized patch clamp data containing missed events. Biophys. J. 70:264-280.

21. Xu, G.M., González-Perrett, S., Essafi, M., Timpanaro, G.A., Montalbetti, N., Arnaout, M.A., and H.F. Cantiello. 2003. Polycystin-1 activates and stabilizes the polycystin-2 channel. J. Biol. Chem. 278(3): 1457-1462.

22. Raychowdhury, M.K., McLaughlin, M., Ramos, A., Montalbetti, N., Bouley, R., Ausiello, D.A., and H.F. Cantiello. 2005. Characterization of single channel currents from primary cilia of renal epithelial cells. J. Biol. Chem. 280: 34718-34722.

23. Lal, S., Scarinci, N., Perez, P.L., Cantero, M.R., and H.F. Cantiello. 2018. Lipid bilayer-atomic force microscopy combined platform records simultaneous electrical and topological changes of the TRP channel polycystin-2 (TRPP2). PLoS One 13(8):e0202029.

24. Hille, B. 1992. Ionic Channels of Excitable Membranes, 2da Edición, Sinauer, Sunderland, MA, 25. Schultz, S.G. 1980. Basic Principles of Membrane Transport, $1^{\text {ra }}$ Edicion. Cambridge university Press, New York.

26. Cantero, M.R., and H.F. Cantiello. 2011. Effect of lithium on the electrical properties of Polycystin-2 (TRPP2). Eur. Biophys. J. 40: 1029-1042.

27. Hodgkin, A.L., and R.D. Keynes. 1955. The potassium permeability of a giant axon nerve fiber. J. Physiol. 128:61-88.

28. Mackey, M., M. McNeel. 1971. The independence principle: a reconsideration. Biophys. J. 11:675-680. 
Calcium Transport Mediated by PC2 - Velázquez et al 2022

29. Hille, B., and W. Schwarz. 1978. Potassium channels as multi-ion single-file pores. J. Gen. Physiol. 72(4):409-442.

30. Nilius, B., Weidema, F., Prenen, J., Hoenderop, J.G., Vennekens, R., Hoefs, S., Droogmans, G., and R.J. Bindels. 2003. The carboxyl terminus of the epithelial $\mathrm{Ca}^{2+}$ channel $\mathrm{ECaC} 1$ is involved in $\mathrm{Ca}^{2+}$ dependent inactivation. Pflügers Arch. 445, 584-588.

31. Cantiello, H.F. Regulation of calcium signaling by polycystin-2. 2004. J. Physiol. 286(6): F1012-F1029.

32. Fall, C.P. Computational Cell Biology. 2002. Chapter 11, Interdisciplinary Applied Mathematics, Vol 20; Springer, New York.

33. Li, Q., Liu, Y., Zhao, W., and X.Z. Chen. 2002.The calcium-binding EF-hand in polycystin-L is not a domain for channel activation and ensuing inactivation. FEBS Lett. 516: 270-278. 